\title{
Advances in High-Power, Ultrashort Pulse DPSSL Technologies at HiLASE
}

\author{
Martin Smrž *, Ondřej Novák, Jiří Mužík, Hana Turčičová, Michal Chyla, Siva Sankar Nagisetty, \\ Michal Vyvlečka, Lukáš Roškot, Taisuke Miura, Jitka Černohorská, Pawel Sikocinski, \\ Liyuan Chen, Jaroslav Huynh, Patricie Severová, Alina Pranovich, Akira Endo and Tomáš Mocek
}

HiLASE Centre, Institute of Physics AS CR, v.v.i., Za radnicí 828, Dolní Břažany 252 41, Czech Republic; ondrej.novak@hilase.cz (O.N.); jiri.muzik@hilase.cz (J.M.); hana.turcicova@hilase.cz (H.T.); michal.chyla@hilase.cz (M.C.); shivashankar.nagisetty@hilase.cz (S.S.N.); michal.vyvlecka@hilase.cz (M.V.); lukas.roskot@hilase.cz (L.R.); taisuke.miura@hilase.cz (T.M.); jitka.cernohorska@hilase.cz (J.Č.); pawel.sikocinski@hilase.cz (P.S.); liyuan.chen@hilase.cz (L.C.); jaroslav.huynh@hilase.cz (J.H.); patricie.severova@hilase.cz (P.S.); alina.pranovich@hilase.cz (A.P.); akira.endo@hilase.cz (A.E.); tomas.mocek@hilase.cz (T.M.)

* Correspondence: martin.smrz@hilase.cz; Tel.: +420-314-007-752

Received: 31 July 2017; Accepted: 25 September 2017; Published: 1 October 2017

\begin{abstract}
The development of kW-class diode-pumped picosecond laser sources emitting at various wavelengths started at the HiLASE Center four years ago. A 500-W Perla C thin-disk laser with a diffraction limited beam and repetition rate of $50-100 \mathrm{kHz}$, a frequency conversion to mid-infrared (mid-IR), and second to fifth harmonic frequencies was demonstrated. We present an updated review on the progress in the development of compact picosecond and femtosecond high average power radiation sources covering the ultraviolet (UV) to mid-IR spectral range at the HiLASE Center. We also report on thin-disk manufacturing by atomic diffusion bonding, which is a crucial technology for future high-power laser development.
\end{abstract}

Keywords: diode-pumped solid-state lasers (DPSSL); high average power lasers; Yb:YAG; mid-infrared radiation; thin-disk laser; higher harmonic generation; picosecond pulses; UV generation; optical parametric amplifier; thin-disk bonding

\section{Introduction}

Compact, $\mathrm{kW}$-class, near-infrared pulsed lasers are becoming highly important for both science and industry. In particular, picosecond and sub-picosecond lasers have turned out to be indispensable tools in laser material processing. They are beneficial primarily for their highly accurate and special processing of many materials, such as the micro-patterning of large surfaces [1-3], or the processing of carbon-reinforced plastics [4]. Specifically, Yb:YAG lasers have lately reached a magic value of an average output power of $1 \mathrm{~kW}$ while their pulse energy exceeded $1 \mathrm{~J} \mathrm{[5],} \mathrm{both} \mathrm{in} \mathrm{burst} \mathrm{mode} \mathrm{[6]} \mathrm{and}$ continuous pulsing $[7,8]$, although often with a pulse length exceeding $10 \mathrm{ps}$.

Rapid progress is also expected in mid-infrared and UV spectral regions. The growth of large volume conversion crystals and the advent of new kinds of nonlinear crystals enables efficient conversion of high average power and high energy picosecond near-infrared (near-IR) pulses with a wavelength of $1 \mu \mathrm{m}$ to deep ultraviolet (UV) [9,10] or mid-infrared (mid-IR) spectral regions [11,12]. This broadens the application potential of near-infrared ultrashort-pulse lasers in high-tech applications. For example, high-power picosecond laser pulses of fundamental and harmonic (up to fifth) frequencies will enable high-speed, high-precision micro- and nano-structuring of large surface areas on various materials with flat-top beams using diffraction optics and interference techniques [13]. Ultrashort laser pulses in the mid-IR spectral range can also open ways for 3D direct laser writing inside biological 
samples, polymer materials, and narrow-bandgap semiconductors which are opaque for visible and near-IR laser light [14]. Furthermore, tunable spectral sources from near-IR to mid-IR at enhanced laser power can improve the sensitivity of infrared spectroscopy in applications for monitoring trace gases in atmosphere and biomedicine [15]. Besides industrial applications, near-IR picosecond pulses are also essential, for example, in THz waves generation [16,17], attosecond science [18], or femtosecond optical parametric chirped pulse amplification (OPCPA) pumping [19].

Near-IR thin-disk lasers also proved their ability to generate high average power short pulses, which are suitable for laser produced plasma-based (LPP) [20], free electron laser-based (FEL) [21,22], or inverse Compton scattering-based (ICS) [23] extreme UV radiation sources. It helps, for example, to construct new stations for semiconductor lithography at $13.5 \mathrm{~nm}$ or $6.7 \mathrm{~nm}$ and to support evolution in electronics. An important requirement for application in lithography is stability of all laser parameters and compactness in the actual application field. Intensive study has been performed at the HiLASE Center to confirm the high beam quality thin-disk laser with good pointing stability $[24,25]$. Higher conversion efficiency from pump pulse to amplified pulse energy is the key to realizing these characteristics. Mid-IR, compact, high average power diode-pumped sources based on Ho-doped materials also have potential to directly pump powerful $\mathrm{CO}_{2}$ lasers, which would make the $\mathrm{CO}_{2}$ lasers more compact for lithographic stations [26].

In this paper, we report on progress in the development of ultrashort pulsed laser technology and laser components development since 2015, when a first review paper was published [27]. The technology of Yb:YAG thin-disk lasers Perla A, B, and C emitting in near-infrared ranges has matured, and goals have been updated to finally exceed $1 \mathrm{~kW}$ of average power and $1 \mathrm{~J}$ of pulse energy in following years (Figure 1). Nowadays, up to $500 \mathrm{~W}$ of average power can be generated. Together with the frequency conversion of these lasers and the construction of a new mid-IR disk laser beamline, the spectral range from UV $(200 \mathrm{~nm})$ to mid-IR $(10 \mu \mathrm{m})$ in picosecond and sub-picosecond temporal range should be covered (Figure 1). This progress, in development since 2015, is summarized in Tables 1 and 2.
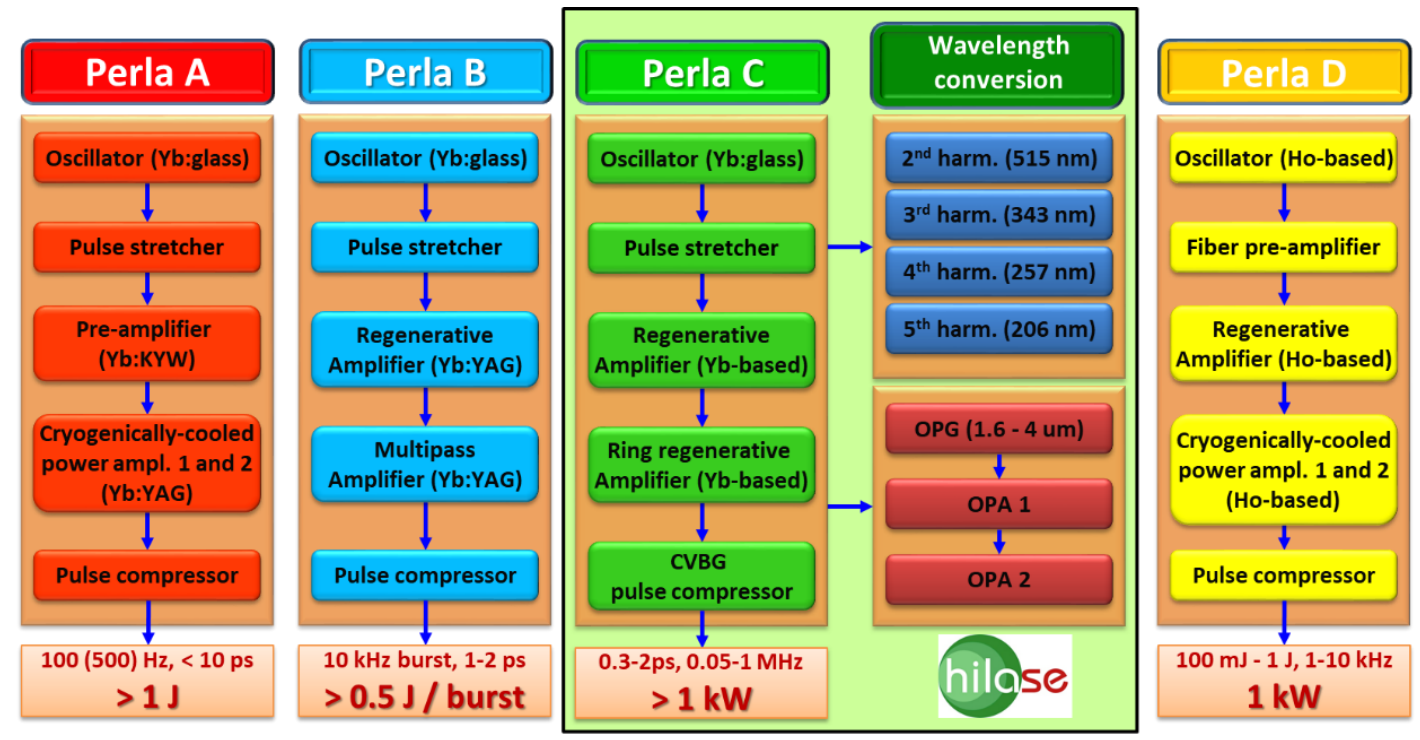

Figure 1. Actual scheme and target parameters of thin-disk based beamlines and frequency conversion stages, which are operated or under construction at the HiLASE Center in 2017. CVBG: chirped volume Bragg grating-based; OPG: optical parametric generation; OPA: optical parametric amplification.

\subsection{Perla Picosecond Thin-Disk Laser Platform}

The development of compact thin-disk-based kW-class thin-disk lasers started at HiLASE several years ago. In-house developed thin-disk platforms [28] at HiLASE recently received the name Perla. 
Several thin-disk Perla platforms with various pulse parameters exist (Figure 1). The most progressive is the continued construction of the high repetition rate platform Perla $C$, which is important for the majority of industrial picosecond laser applications including applications in lithography. The Perla $\mathrm{C}$ system based on a regenerative amplifier aims for $1 \mathrm{~kW}$ of average power at a variable repetition rate $50-1000 \mathrm{kHz}[29,30]$. Nowadays, the system can be operated up to $500 \mathrm{~W}$.

The design of the Perla $\mathrm{C}$ is based on a common CPA (Chirped Pulse Amplification) method. A low pulse energy (nJ) Yb-doped fiber oscillator producing several picosecond-long chirped pulses with a 20-nm bandwidth (full width at half maximum (FWHM)) is followed by fiber preamplifiers, two stage thin-disk regenerative amplifiers, and a highly dispersive chirped volume Bragg grating-based (CVBG) pulse compressor (chirp rate $220 \mathrm{ps} \mathrm{nm}^{-1}$, full bandwidth $4 \mathrm{~nm}$ ). The design specification of this system is targeted to $5 \mathrm{~mJ}$ of pulse energy at $100 \mathrm{kHz}$ repetition rate; however, upon requirement, the system was modified for $50 \mathrm{kHz}$ operation up to $500 \mathrm{~W}$ of average power. Prospectively, the adjustability of the repetition rate from $50 \mathrm{kHz}$ to $1 \mathrm{MHz}$ at $0.5 \mathrm{~kW}$ of average power should be enabled by the installation of a new high-voltage Pockels cell driver. The research trial also aimed to upgrade the system to the level of 1-kW of average power by keeping the repetition rate unchanged, i.e., $100 \mathrm{kHz}$. Thin disks used in the regenerative amplifiers are diamond-bonded Yb:YAG single crystals (220 $\mu \mathrm{m}$ thick, 7 at. \% doping) continuously pumped at the zero-phonon-line wavelength $(968.8 \mathrm{~nm})[24,25]$.

The optical setup of the first-stage regenerative amplifier [31] includes a standing-wave cavity, thin-disk laser head with a pump spot diameter of $2.8 \mathrm{~mm}$, a $500 \mathrm{~W}$ continuous wave (CW) pump diode laser, and a dual beta barium borate (BBO) crystal (each $8 \times 8 \times 25 \mathrm{~mm}^{3}$ ) and a Pockels cell to enable the fast switching on and off of the system. The maximum output pulse energy from this first regenerative amplifier before compression is $1.2 \mathrm{~mJ}$ (average output power of $120 \mathrm{~W}$ ) at a pump power of $430 \mathrm{~W}$ in a nearly diffraction-limited beam $\left(\mathrm{M}^{2} \approx 1.4\right)$. Optical-to-optical efficiency therefore reaches $29 \%$. A maximum efficiency of $33 \%$ is reached at $1 \mathrm{~mJ}$ pulse energy, i.e., $100 \mathrm{~W}$ of average power. Compressed pulses were obtained with the CVBG compressor (net-efficiency $85 \%$ ) and the duration of $1.3 \mathrm{ps}$.

The second-stage amplifier is seeded by a fraction of the uncompressed output of the first stage $(\approx 20 \mathrm{~W}, 200 \mu \mathrm{J})$. The thin disk is pumped by a CW, 968.8-nm fiber-coupled diode laser on a pump spot with a diameter of $5.2 \mathrm{~mm}$. The disk is located in a ring cavity with two V-passes through the disk per one roundtrip, and the footprint area of the amplifier is only $100 \times 60 \mathrm{~cm}^{2}$. A dual Pockels cell equipped by BBO crystals with dimensions of $10 \times 10 \times 25 \mathrm{~mm}^{3}$ for each of the crystals placed in in-house developed holders is operated at a half-wave voltage of $10-\mathrm{kV}$ and a repetition rate of 50 or $100 \mathrm{kHz}$. A maximum CW output power of $565 \mathrm{~W}$ was obtained at $1.21 \mathrm{~kW}$ pump power, and the optical-to-optical efficiency was $47 \%$. In seeded operation with the input pulse energy of $0.2 \mathrm{~mJ}$, obtained pulses were $4.5 \mathrm{~mJ}$ at $100 \mathrm{kHz}$ ( $450 \mathrm{~W}$ average output power) with an extraction efficiency of $43 \%$, as shown in Figure 2a. Pulses compressed by a CVBG compressor with a net-efficiency of approximately $85 \%$ have a 1.4-nm bandwidth (FWHM) and a pulse duration of $1.8 \mathrm{ps}$ (FWHM). In the $50-\mathrm{kHz}$, regime we generated $9 \mathrm{~mJ}$ pulses ( $450 \mathrm{~W}$, uncompressed) with $1130 \mathrm{~W}$ of pump power, i.e., optical-to-optical efficiency reached an excellent value of almost $40 \%$. The repetition rate of the laser system is planned to be tunable from $50 \mathrm{kHz}$ to $1 \mathrm{MHz}$ after completing an appropriate Pockels cell driver. In the $50-\mathrm{kHz}$ regime, a several-hours-long stable operation was demonstrated with an average output power of $320 \mathrm{~W}(6.4 \mathrm{~mJ})$ in fundamental transverse mode, as shown in Figure $2 \mathrm{~b}$. The laser was operated for $10 \mathrm{~h}$ at $330 \mathrm{~W}$ with a power fluctuation root mean square as low as $1.2 \%$ (root mean square value (RMS)). Because of rising compressor depolarization losses at full output power, dispersion detuning, and beam deformation caused by high CVBG temperature, the optimization of the pulse compression and output pulse shape is ongoing. The performance of the Perla $C$ laser system is studied in the entire range of its repetition rates and optimized pulse compression, and a concept for a 1-kW, sub-picosecond upgrade is included in the present research subjects. 
Table 1. Comparison of progress in typical average output power, pulse energy, pulse repetition rate, pulse length (full width at half maximum (FWHM)), and beam quality of Perla thin-disk laser platforms achieved since 2015 [27].

\begin{tabular}{ccccc}
\hline Year & Perla A & Perla B & Perla C & Perla D \\
\hline \multirow{2}{2015}{} & Not available & $45 \mathrm{~mJ} ; 1 \mathrm{kHz} ; 45 \mathrm{~W}$ & $1 \mathrm{~mJ} ; 1 \mathrm{kHz} ; 90 \mathrm{~W} ; 1.9 \mathrm{ps}$ & Not available \\
\hline \multirow{4}{*}{$\mathbf{2 0 1 7}$} & $100 \mathrm{~mJ} ; 10 \mathrm{~Hz}$ & $45 \mathrm{~mJ} ; 1 \mathrm{kHz} ; 45 \mathrm{~W} ;$ & $9 \mathrm{~mJ} ; 50 \mathrm{kHz} ; 450 \mathrm{~W} ;$ or & \\
& proof-of-principle & $<1 \mathrm{ps}, \mathrm{M}^{2}<1.3$, & $4.5 \mathrm{~mJ} ; 100 \mathrm{kHz} ; 450 \mathrm{~W} ;$ & Under design \\
& experiments, under & Also new: & $1.3 \mathrm{ps}, \mathrm{M}^{2}<1.5-2 ;$ & \\
\hline
\end{tabular}

Table 2. Comparison of progress in typical average output power, pulse repetition rate, and conversion efficiency of frequency up- and down-conversion stages pumped by the picosecond Perla $\mathrm{C}$ thin-disk laser platform since 2015 [27]. Mid-IR OPG: optical parametric generation producing mid-infrared pulses; Mid-IR OPA: optical parametric amplification amplifying mid-infrared pulses.

\begin{tabular}{|c|c|c|c|c|}
\hline Year & $\begin{array}{c}\text { Second Harmonic } \\
515 \mathrm{~nm}\end{array}$ & $\begin{array}{c}\text { Fourth Harmonic } \\
257.5 \mathrm{~nm}\end{array}$ & $\begin{array}{l}\text { Fifth Harmonic } \\
205 \mathrm{~nm}\end{array}$ & $\begin{array}{c}\text { Mid-IR OPG + OPA } \\
1.5-3 \mu \mathrm{m}\end{array}$ \\
\hline 2015 & $\begin{array}{c}11 \mathrm{~W} ; 100 \mathrm{kHz} ; 40 \% \\
\text { conversion } \\
\text { efficiency }\end{array}$ & $\begin{array}{c}2 \mathrm{~W} ; 100 \mathrm{kHz} ; 18 \% \\
\text { conversion } \\
\text { efficiency }\end{array}$ & Not available & Under design \\
\hline 2017 & $\begin{array}{c}40 \mathrm{~W} ; 100 \mathrm{kHz} ; 56 \% \\
\text { conversion } \\
\text { efficiency }\end{array}$ & $\begin{array}{c}6 \mathrm{~W} ; 100 \mathrm{kHz} ; 18 \% \\
\text { conversion } \\
\text { efficiency }\end{array}$ & $\begin{array}{c}0.8 \mathrm{~W} ; 100 \mathrm{kHz} \\
20 \% \text { conversion } \\
\quad \text { efficiency }\end{array}$ & $\begin{array}{c}1.7-2.6 \mu \mathrm{m} \text { tunability (both } \\
\text { signal + idller waves); } \\
8.5 \mathrm{~W} \text { signal }(<2 \mu \mathrm{m}) ; \\
5 \mathrm{~W} \text { idler }(>2 \mu \mathrm{m}) \\
77 \mathrm{kHz}\end{array}$ \\
\hline
\end{tabular}

\section{(a)}

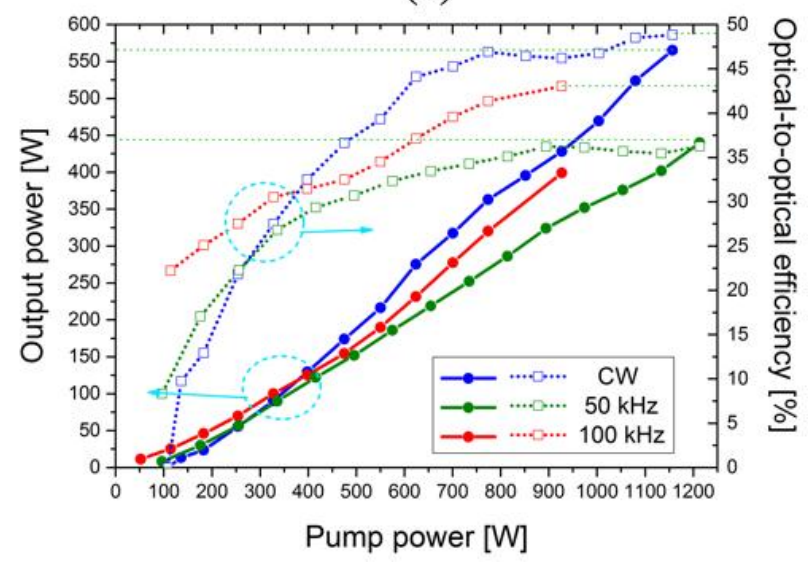

(b)

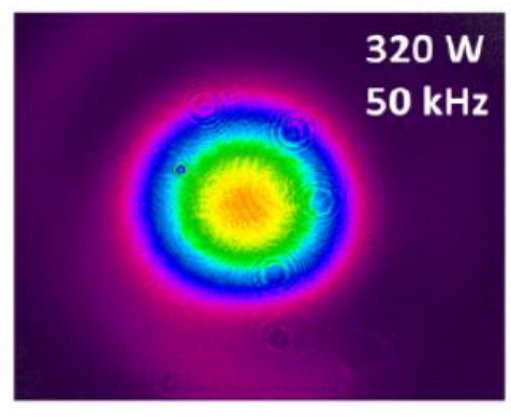

Figure 2. Typical performance of the actual status of the Perla $\mathrm{C}$ amplifier with a ring cavity: (a) Output power and optical-to-optical efficiency in pulsed operation (50 and $100 \mathrm{kHz}$ ) compared with continuous wave (CW) performance of the ring cavity; (b) nearly diffraction-limited beam profile (Gaussian, normalized, red - peak power, blue - low power, violet - background) at average power of $320 \mathrm{~W}$ and $50 \mathrm{kHz}$ repetition rate as used for experiments $\left(\mathrm{M}^{2}<1.8\right)$.

\subsection{Perla A and Perla B Platforms}

Both the Perla A and Perla B platforms are CPA systems, which aim to high energy pulses. The Perla B was redesigned [32] in order to provide a burst of pulses and better fit experimental requirements. Intra-burst repetition rate was set to $10 \mathrm{kHz}$, and a burst repetition rate of $100 \mathrm{~Hz}$ with optional switching back to original configuration operating continuously at a repetition rate of $1 \mathrm{kHz}$ was described in detail in References [24,27]. In the burst mode, each 1-ms long pulse burst 
consists of ten 1-2-ps long pulses. The pulses are generated from an $\mathrm{Yb}$-doped fiber oscillator (nJ pulse energy), stretched to $1.5 \mathrm{~ns}$ by a chirped-fiber Bragg grating stretcher, and preamplified in a system of fiber preamplifiers to approximately $10 \mu \mathrm{J}$. A $100-\mu \mathrm{J}$ pulse burst is after the preamplification seeded to a thin disk-based regenerative amplifier and amplified to $10 \mathrm{~mJ}$ per pulse, i.e., $100 \mathrm{~mJ}$ per burst. The amplifier is quasi-continuous wave (QCW) pumped (1 ms pulse length) by fiber-coupled laser diodes at zero-phonon line wavelength $(968.8 \mathrm{~nm})$, and is switched on and off by a pair of $10 \times 10 \times$ $22 \mathrm{~mm}^{3} \mathrm{BBO}$ crystals. The output beam is nearly diffraction-limited, and the $\mathrm{M}^{2}$ parameter measured for continuous pulsing at $1 \mathrm{kHz}$ was better than 1.3.

Finally, the amplified pulses will be boosted up to $600 \mathrm{~mJ}$ per burst in a 10-pass thin disk-based multipass amplifier. The amplifier is pumped at $940 \mathrm{~nm}$ by a fiber-coupled laser diode module $(2 \mathrm{~kW})$. Both the amplification stages employ a diamond-bonded Yb:YAG thin-disk with a thickness of $220 \mu \mathrm{m}$, 7 at. \% doping concentration, and an 8-mm clear aperture; however, the first regenerative amplifier uses only $4 \mathrm{~mm}$ of the diameter of the aperture. Prospectively, the output could be boosted by adding a booster amplifier equipped by large size thin disks with an energy extraction of $1.5 \mathrm{~J}$ or $3 \mathrm{~J}$ per burst, depending on the disk size and pump module available [32]. Pulse compression of the pulse burst is realized by an multi-layer dielectric (MLD)-based grating compressor. Reaching sub-1-ps pulses is expected, as it was already demonstrated on the $45-\mathrm{mJ}$ pulses. A demonstration of the multipass amplifier at full power is planned in 2018.

The Perla A is a new platform based on cryogenically-cooled disk laser technology. Laser operation of quasi-three-level Yb:YAG gain media at low temperature brings many advantages such as higher thermal conductivity, which is almost $4 \times$ higher at $100 \mathrm{~K}$ for 1 at. $\%$ Yb-doping then the room temperature thermal conductivity, lower thermo-optical coefficient (at $100 \mathrm{~K}$, approximately one eighth of its original value at room temperature), and lower thermal expansion coefficient (at $100 \mathrm{~K}$, one third of the room temperature value) [33]. These properties significantly improve the laser cooling efficiency and reduce effects like thermal lensing, which usually prevent lasing at high power and room temperature operation. On the other hand, low temperature operation shrinks the emission bandwidth of Yb:YAG more than six times to approximately $1.5 \mathrm{~nm}$ (FWHM) [34], and the achievable pulse length is longer than for room temperature operation. It normally approaches $10 \mathrm{ps}$ [5].

Development of the cryogenic Perla A platform has started this year and the system is still under design. The platform front-end will consist of an $\mathrm{Yb}$-doped fiber oscillator providing $\mu \mathrm{J}$ pulses, and $\mathrm{Yb}: \mathrm{KYW}$ bulk, room-temperature-operated preamplifier reaching output pulse energy of 10-20 mJ at $1 \mathrm{kHz}$ repetition rate, due to the prospective upgrade of the whole system to $1 \mathrm{kHz}$. Yb:KYW was chosen because of the good overlap of its peak wavelength and the wavelength of cryogenically-cooled $\mathrm{Yb}: Y A G$, whose peak emission shifts to shorter wavelengths as the temperature decreases. The pulses from the Yb:KYW amplifier will be seeded to a cryogenically-cooled Yb:YAG single slab four-pass amplifier with ceramic Yb:YAG gain medium with saturable absorber cladding and will boost the pulse to $100 \mathrm{~mJ}$. Final, power amplification is planned by a new design of a liquid nitrogen-cooled Yb:YAG thin-disk laser, which is still under technical consideration. The expected pulse energy is about $1.2 \mathrm{~J}$ in a diffraction-limited beam and $100 \mathrm{~Hz}$ repetition rate with a potential of a 1-kHz upgrade. Due to emission bandwidth shrinking at low temperatures, bandwidth-limited pulse length prolongs and will probably reach 10 ps after compression. Behavior of the single slab gain medium in a closed-loop He cryostat for the Perla A preamplifier was already studied at low temperatures, both experimentally and theoretically, in Reference [35]. Commissioning of the system at full power is scheduled by the end of 2019.

\subsection{Atomic Difusion Bonding (ADB)}

Critical components for thin-disk laser development are high-quality, efficiently cooled thin disks. Since the disks themselves are very thin and fragile, they are carried by a heatsink with high thermal conductivity. The bonding layer between the gain medium and the heatsink must be highly thermally conductive, as well as mechanically rigid in order to withstand high operating temperatures and 
mechanical stresses caused by thermal gradients during the laser operation. Thin disks are often bonded to a metallic heatsink by indium-based metallic solder. Such a connection is not perfectly homogeneous; the thermal conductivity of such a contact is insufficient for $\mathrm{kW}$ class lasers, and creates a bottleneck for efficient heat extraction. Soldering also generates residual mechanical stresses in the gain medium. Therefore, the usual approach is to use a special epoxy bonding to a diamond heatsink. We employed another technique for the first time, so-called Atomic Difusion Bonding (ADB) [36], which is an epoxy-free process based on the recrystallization of the contacting layers, which thus allows the formation of a perfect thermal bridge [37].

The first demonstration of the ADB process was realized by the bonding of $\mathrm{Yb}$ :YAG to an $\mathrm{Al}$ heatsink (Figure 3). Nanocrystalline Au films were deposited on both Yb:YAG and Al heatsink surfaces with Ti underlayers, as shown in Figure 3. The Ti underlayers enhanced the adhesion strength of the deposited films on the bonded surface and controlled the crystallographic orientation of the deposited films. Au-layer-coated surfaces were bonded at room temperature under high vacuum environment and pressure application. During this procedure, the Au film recrystallizes and creates a single metallic layer. ADB with extremely thin Au films ensures better thermal management, mechanical tolerances, and prevention of the out-gassing of materials in a vacuum or high temperature environment. The strength of the connection depends on film thickness, surface cleanliness, and the quality of surface polishing. Since the thickness of the nanocrystalline layer can be controlled within a certain percentage of variation, such a uniform bonding interface offers the fabrication of a laser active medium with tight tolerances on thickness. Unlike thermal diffusion bonding or soldering, no annealing or curing at high temperatures is required, making it possible to work with materials of different coefficients of thermal expansion.
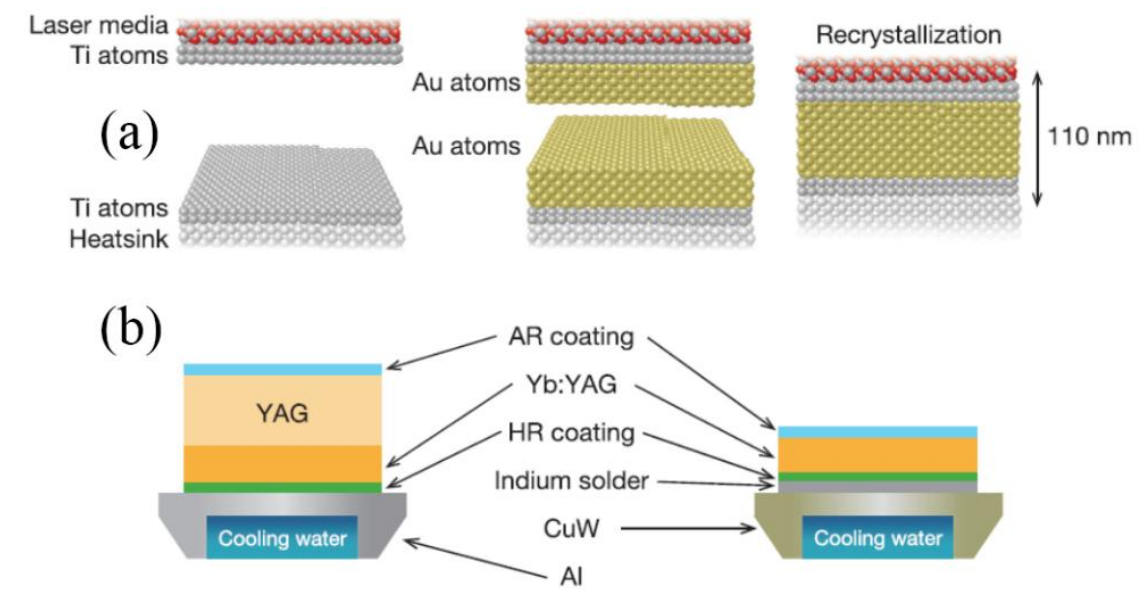

Figure 3. Process of Atomic Difusion Bonding (ADB): (a) Thin nanocrystalline Au films are deposited on the precisely polished and coated Yb:YAG and the Al heatsink surfaces at room temperature by the vacuum sputtering process. The bonding is accomplished in air by contacting the two Au surfaces and pressing. Recrystallization occurs at the $\mathrm{Au}-\mathrm{Au}$ contact interface and the two surfaces can be bonded together without the use of adhesives or heat; (b) Schematic diagram of Yb:YAG/YAG composite ceramic thin disk on the Al heatsink fixed by the ADB technique (left) and commercially available Yb:YAG thin disk on the CuW heatsink fixed by soldering (right) [36].

We experimentally compared the potential of commercially available indium-soldered Yb:YAG thin disks and ADB bonded Yb:YAG/YAG composite ceramics thin disks [38]. It was proven that the peak surface temperature of ADB disk pumped at $280 \mathrm{~W}\left(4.5 \mathrm{~kW} \mathrm{~cm}^{-2}\right.$ for the incident pump beam) is $57^{\circ} \mathrm{C}$ lower than the temperature of the soldered disk under identical operating conditions. By a thin-disk surface deformation measurement setup developed at HiLASE [37], we also demonstrated the different mechanical behaviors of the disk when pump radiation is applied. The CW output power reached in the proof of principle experiment was $100 \mathrm{~W}$ and $177 \mathrm{~W}$ from the soldered and the ADB 
disk, respectively. A new series of ADB disks with optimized gain medium and bonding procedure parameters with metallic and dielectric heatsinks for $\mathrm{kW}$ lasers is now under preparation.

\section{Mid-IR Picosecond Pulse Generation}

Sources at wavelengths in the mid-IR range (between 2 and $8 \mu \mathrm{m}$ ) are under development due to their important applications [11,39], such as minimally-invasive neurosurgery and plastic and polymer processing. Scientific applications, for instance high harmonic generation [40], dielectric laser acceleration [41], or vibrational spectroscopy [42], also benefit from the use of a mid-IR source.

A high average power wavelength tunable picosecond mid-IR source based on optical parametric generation (OPG) and amplification (OPA) in a nonlinear optical crystal is being developed. In this parametric down-conversion process, a powerful pump beam of the shortest wavelength generates signal and idler beams of longer wavelengths. In the wavelength conversion setup (Figure 4), the $\mathrm{Yb}: \mathrm{YAG}$ thin-disk laser delivers the pump beam of $100 \mathrm{~W}$ average power at a repetition rate of $77 \mathrm{kHz}$, wavelength of $1030 \mathrm{~nm}$, and pulse width of about 2 ps. Part of this fundamental beam pumps an OPG in a 10-mm long, periodically poled lithium niobate crystal (PPLN). The generated wavelength is determined by the PPLN's poling period and temperature. Tunability of the signal wavelength between $1.46 \mu \mathrm{m}$ and $1.95 \mu \mathrm{m}$ was achieved. The corresponding idler wavelengths were in the range of $2.18 \mu \mathrm{m}$ to $3.50 \mu \mathrm{m}$. The signal beam up to $80 \mathrm{~mW}$ was generated at $2 \mathrm{~W}$ of pump power, when the double pass of the beams through the PPLN crystal was employed.

The main part of the pump beam is delivered into an OPA stage, in which the signal beam from the OPG stage is amplified. The stage consists of two 10-mm long potassium titanyl phosphate (KTP) crystals arranged in the walk-off compensating arrangement. Signal and idler tunability between $1.70-1.95 \mu \mathrm{m}$ and $2.18-2.62 \mu \mathrm{m}$, respectively, was demonstrated by changing the phase-matching angle in KTP crystals. The signal beam was amplified up to $8.5 \mathrm{~W}$ at $42 \mathrm{~W}$ pump. The power of the generated idler was up to $5 \mathrm{~W}$.

Improvements of the system for the achievement of higher output powers and broader tuning ranges were proposed. These are based on higher pump power, another OPA stage, and the use of Potassium Titanyle Arsenate (KTA) crystals, which have a broader transparency range in comparison to KTP crystals. Thermal effects caused by residual absorption [43] of the beams in nonlinear optical crystals at high average power will be studied as well.

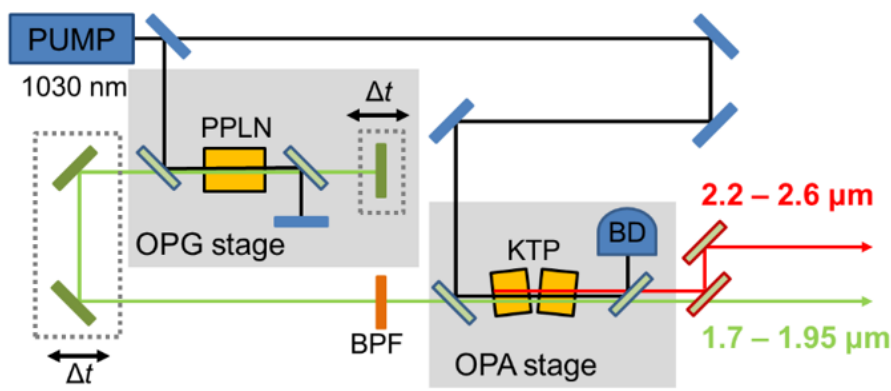

(a)

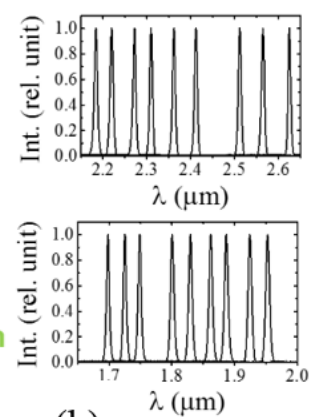

(b)

Figure 4. Tunable picosecond optical parametric generator (OPG) followed by optical parametric amplifier stage (OPA): (a) Optical scheme of the frequency conversion system (PPLN-periodically polled lithium niobate, BPF-bandpass filter, BD—beam dump, PUMP-Perla C thin-disk laser, KTP—potassium titanyl phosphate, $\Delta \mathrm{t}$-delay line); (b) Spectral tunability of idler (top) and signal (bottom) beams.

Besides the OPG/OPA-based mid-IR source of radiation, a six-year project on the development of a Ho-doped picosecond thin-disk laser system emitting near $2.1 \mu \mathrm{m}$ is starting at HiLASE to support OPA in the 4-6 um spectral region (Perla D in Figure 1). In the first phase, a 100-W regenerative 
amplifier with a 10-kHz repetition rate and a fully Ho-doped fiber-based front-end will be constructed. In the second phase, we are planning to boost pulse energy in order to generate 1-J picosecond pulses and $1 \mathrm{~kW}$ of average power. All of the Ho-based systems will be pumped by Tm-doped CW fiber lasers, which are under construction now. Detailed technical concept is still under consideration. Direct applications for this kind of laser system besides OPA pumping are modifications of semiconductors, processing of plastics, laser-induced damage threshold measurement, etc.

\section{Harmonics Generation}

Various applications benefit from higher photon energy in visible, UV, and DUV (Deep Ultraviolet) wavelength ranges, which can better match the absorption of materials such as copper, carbon fiber-reinforced plastics, glasses, etc. When the picosecond pulses are considered, the laser-matter interaction is specified by a very small heat-affected zone. Therefore, the pulses of $100 \mathrm{~W}, 100 \mathrm{kHz}$, $1030 \mathrm{~nm}$ first Perla C amplifier were converted into harmonic frequencies in order to fulfill the requirements of user experiments. For the harmonics generation, we use borate crystals LBO (lithium triborate), $\mathrm{BBO}$ (beta-barium borate), and CLBO (cesium lithium borate) due to their suitable properties, such as relatively high nonlinear coefficient, high transparency, and commercial availability [44]. The second harmonic $(515 \mathrm{~nm})$ of the fundamental beam is generated in the LBO crystal (Type I phase-matching (PM), $8 \times 8 \mathrm{~mm}$ aperture, $10 \mathrm{~mm}$ long, antireflective (AR) coated on both sides for $1030 \mathrm{~nm}$ and $515 \mathrm{~nm}$, routine conversion efficiency of 56\%) at the output powers up to $40 \mathrm{~W}$ (for $70 \mathrm{~W}$ input), and it is further is used for the generation of the third and fourth harmonics in cascade conversions (Figure 5). The power of the third harmonic-achieved by $2 \omega+1 \omega$ sum frequency generation in an LBO crystal (Type II PM, AR/AR@1030 + $515+343 \mathrm{~nm}, 8 \times 8$ mm, $5 \mathrm{~mm}$ long, conversion efficiency of $35 \%$ related to the second harmonic), placed just behind the first LBO, without any optimization-is $6.7 \mathrm{~W}$, and will soon be a subject of the next system upgrades. The fourth harmonic $(257.5 \mathrm{~nm})$ in the DUV range is produced either in the $\mathrm{BBO}(8 \times 8 \mathrm{~mm}, 3 \mathrm{~mm}$ long, with AR/AR@515 + $257.5 \mathrm{~nm}$, conversion efficiency of $14 \%$ related to the second harmonic) or CLBO $(6 \times 6 \mathrm{~mm}, 6 \mathrm{~mm}$ long, uncoated) crystals (both Type I PM) by the second harmonic generation of a 515-nm beam. The output power was up to $6 \mathrm{~W}$ at the conversion efficiency of about $18 \%$ (related to the second harmonic, neglecting the Fresnel reflections), while the CLBO crystal resulted as a better convertor showing higher output power without a trend for saturation in efficiency [9]. The fifth harmonic ( $206 \mathrm{~nm}$ ) is realized by $4 \omega+1 \omega$ sum frequency generation in a CLBO crystal (Type I PM, $12 \times 12 \mathrm{~mm}, 4 \mathrm{~mm}$ long, uncoated, conversion efficiency of $20 \%$ related to the fourth harmonic) at the output power of $0.8 \mathrm{~W}$ [45]. The ovens with the crystals for the DUV radiation are placed in a metal box filled with argon so as to protect the crystal surfaces against moisture and DUV light-generated ozone. The CLBO crystals are always kept at a recommended temperature of $150{ }^{\circ} \mathrm{C}$ to prolong their lifetime [46]. The present values of the harmonics outputs derived from the Perla $C$ beam (first regenerative amplifier only) are the values after a long-term operation of the system and do not represent the fully optimized fundamental beam (e.g., higher orders of pulse dispersion were not fully compensated).

When the 1-kW, 1-MHz upgrade of the thin-disk amplifiers is accomplished, it will be used for harmonic generation as well. The second and third harmonic aims to reach $500 \mathrm{~W}$ and $400 \mathrm{~W}$, respectively. Up to $100 \mathrm{~W}$ average power should be generated in the DUV. The increased thermal issues, which normally lead to phase mismatch and conversion efficiency reduction, will be decreased by the sandwich structure of a transparent heat spreader and nonlinear crystal or actively cooled multi-plate design of the harmonic generation stage. 


\section{$100 \mathrm{kHz}$}
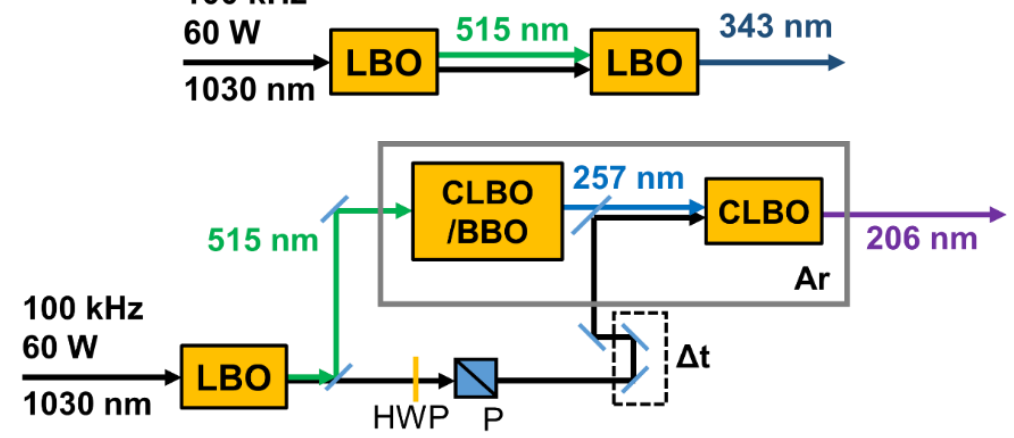

Figure 5. Optical scheme of the frequency conversion system to visible and UV radiation. Second and third harmonic frequency conversion (top); fourth and fifth harmonic frequency (bottom). LBO: lithium triborate; CLBO: cesium lithium borate; BBO: beta barium borate.

\section{Conclusions}

Development of reliable and compact kW-class thin-disk-based picosecond lasers continues at the HiLASE Center. We demonstrated Perla thi- disk platforms for the delivery of high repetition rates and high energy ultrashort pulses. The Perla $C$ regenerative amplifier routinely generates pulses up to almost $500 \mathrm{~W}$ of average power. The application potential of Yb:YAG Perla beamlines is broadened by conversion to harmonic frequencies from second to fifth ones, and by OPG and OPA to mid-IR. Lately, we have also started the development of a cryogenically-cooled thin-disk laser beamline for $\mathrm{Yb}: Y A G$ or Ho-based pulsed lasers with a goal to generate a 1-kW picosecond beam at 1.03 and $2.1 \mu \mathrm{m}$, respectively. In our development, we employ several unique solutions such as CVBG compressors for high average power pulses or atomic diffusion bonding for the preparation of in-house made Yb:YAG thin disks.

Acknowledgments: This work is funded by the European Regional Development Fund and the state budget of the Czech Republic (project HiLASE CoE: Grant No. CZ.02.1.01/0.0/0.0/15_006/0000674) and by the European Union's Horizon 2020 research and innovation programme under grant agreement No. 739573. This work was also supported by the Ministry of Education, Youth, and Sports of the Czech Republic (Programmes NPU I Project No. LO1602, and Large Research Infrastructure Project No. LM2015086), and by the Czech Science Foundation (GACR) under project No. GA16-12960S, and by the Technology Agency of the Czech Republic (TACR) under project No. TF03000055 and TG02010056.

Author Contributions: Martin Smrž and Jiří Mužík designed and constructed Perla C beamline; Ondřej Novák proposed conceptual scheme of the mid-IR frequency conversion and designed all the subsequent tasks and experiments; Michal Vyvlečka and Lukáš Roškot carried out mid-IR frequency conversion experiments; Hana Turčičová designed and carried out harmonic frequency conversion experiments; Michal Chyla proposed optical scheme of the Perla B beamline and built front-end and the first amplifier of the beamline; Siva Sankar Nagisetty is building second amplifier of the Perla B beamline and together with Taisuke Miura and Patricie Severová carried out experiments testing the atomic diffusion bonding capabilities; Taisuke Miura proposed concept of Perla A to Perla C beamlines and proposed target parameters; Jitka Černohorská and Martin Smrž designed the Perla D beamline; Pawel Sikocinski, Liyuan Chen, and Akira Endo designed the Perla A beamline; Jaroslav Huynh participated on the Perla A and Perla C experiments; Alina Pranovich participated on fiber front-end experiments for Perla beamlines; Akira Endo and Tomáš Mocek were directing the research. All authors contributed to the scientific discussions, writing and revision of the manuscript.

Conflicts of Interest: The authors declare no conflict of interest.

\section{References}

1. Bonse, J.; Hoehm, S.; Kirner, S.V.; Rosenfeld, A.; Krueger, J. Laser-induced periodic surface structures-A scientific evergreen. IEEE J. Sel. Top. Quantum Electron. 2017, 23, 1-15. [CrossRef]

2. Neuenschwander, B.; Jaeggi, B.; Schmid, M.; Hennig, G. Surface structuring with ultra-short laser pulses: Basics, limitations and needs for high throughput. Phys. Procedia 2014, 56, 1047-1058. [CrossRef] 
3. Wu, B.; Deng, L.; Liu, P.; Zhang, F.; Duan, J.; Zeng, X. Effects of picosecond laser repetition rate on ablation of Cr12MoV cold work mold steel. Appl. Surf. Sci. 2017, 409, 403-412. [CrossRef]

4. Freitag, C.; Wiedenmann, M.; Negel, J.; Loescher, A.; Onuseit, V.; Weber, R.; Ahmed, M.A.; Graf, T. High quality processing of CFRP with a $1.1 \mathrm{~kW}$ picosecond laser. Appl. Phys. A 2015, 119, 1237-1243. [CrossRef]

5. Baumgarten, C.; Pedicone, M.; Bravo, H.; Wang, H.; Yin, L.; Menoni, C.S.; Rocca, J.J.; Reagan, B.A. 1 J, 0.5 kHz repetition rate picosecond laser. Opt. Lett. 2016, 41, 3339-3342. [CrossRef] [PubMed]

6. Schulz, M.; Riedel, R.; Willner, A.; Düsterer, S.; Prandolini, M.J.; Feldhaus, J.; Faatz, B.; Rossbach, J.; Drescher, M.; Tavella, F. Pulsed operation of a high average power Yb:YAG thin-disk multipass amplifier. Opt. Express 2012, 20, 5038-5043. [CrossRef] [PubMed]

7. Negel, J.P.; Loescher, A.; Voss, A.; Bauer, D.; Sutter, D.; Killi, A.; Ahmed, M.A.; Graf, T. Ultrafast thin disk multipass amplifier delivering $1.4 \mathrm{~kW}(4.7 \mathrm{~mJ}, 1030 \mathrm{~nm})$ average power converted to $820 \mathrm{~W}$ at $515 \mathrm{~nm}$ and $234 \mathrm{~W}$ at $343 \mathrm{~nm}$. Opt. Express 2015, 23, 21064-21077. [CrossRef] [PubMed]

8. Nubbemeyer, T.; Kaumanns, M.; Ueffing, M.; Gorjan, M.; Alismail, A.; Fattahi, H.; Brons, J.; Pronin, O.; Barros, H.G.; Major, Z.; et al. 1 kW, 200 mJ picosecond thin-disk laser system. Opt. Lett. 2017, 42, 1381-1384. [CrossRef] [PubMed]

9. Novak, O.; Turcicova, H.; Smrz, M.; Miura, T.; Endo, A.; Mocek, T. Picosecond green and deep ultraviolet pulses generated by a high-power $100 \mathrm{kHz}$ thin-disk laser. Opt. Lett. 2016, 41, 5210-5213. [CrossRef] [PubMed]

10. Chang, C.L.; Krogen, P.; Liang, H.; Stein, G.J.; Moses, J.; Lai, C.J.; Siqueira, J.P.; Zapata, L.E.; Kärtner, F.X.; Hong, K.H. Multi-mJ, kHz, ps deep-ultraviolet source. Opt. Lett. 2015, 40, 665-668. [CrossRef] [PubMed]

11. Petrov, V. Parametric down-conversion devices: The coverage of the mid-infrared spectral range by solid-state laser sources. Opt. Mater. 2012, 34, 536-554. [CrossRef]

12. Hong, K.H.; Huang, S.W.; Moses, J.; Fu, X.; Lai, C.J.; Cirmi, G.; Sell, A.; Granados, E.; Keathley, P.; Kärtner, F.X. High-energy, phase-stable, ultrabroadband $\mathrm{kHz}$ OPCPA at $2.1 \mu \mathrm{m}$ pumped by a picosecond cryogenic Yb:YAG laser. Opt. Express 2011, 19, 15538-15548. [CrossRef] [PubMed]

13. Klein-Wiele, J.H.; Bekesi, J.; Simon, P. Sub-micron patterning of solid materials with ultraviolet femtosecond pulses. Appl. Phys. A 2004, 79, 775-778. [CrossRef]

14. Grojo, D.; Leyder, S.; Delaporte, P.; Marine, W.; Sentis, M.; Utéza, O. Long-wavelength multiphoton ionization inside band-gap solids. Phys. Rev. B 2013, 88, 195135. [CrossRef]

15. Curl, R.F.; Tittel, F.K. Tunable infrared laser spectroscopy. Annu. Rep. Prog. Chem. Sect. C Phys. Chem. 2002, 98, 219-272. [CrossRef]

16. Ochi, Y.; Nagashima, K.; Maruyama, M.; Tsubouchi, M.; Yoshida, F.; Kohno, N.; Mori, M.; Sugiyama, A. $\mathrm{Yb}$ :YAG thin-disk chirped pulse amplification laser system for intense terahertz pulse generation. Opt. Express 2015, 23, 15057-15064. [CrossRef] [PubMed]

17. Huang, S.W.; Granados, E.; Huang, W.R.; Hong, K.H.; Zapata, L.E.; Kärtner, F.X. High conversion efficiency, high energy terahertz pulses by optical rectification in cryogenically cooled lithium niobate. Opt. Lett. 2013, 38, 796-798. [CrossRef] [PubMed]

18. Huang, S.W.; Cirmi, G.; Moses, J.; Hong, K.H.; Bhardwaj, S.; Birge, J.R.; Chen, L.J.; Li, E.; Eggleton, B.J.; Cerullo, G.; et al. High-energy pulse synthesis with sub-cycle waveform control for strong-field physics. Nat. Photonics 2011, 5, 475-479. [CrossRef]

19. Fattahi, H.; Barros, H.G.; Gorjan, M.; Nubbemeyer, T.; Alsaif, B.; Teisset, C.Y.; Schultze, M.; Prinz, S.; Haefner, M.; Ueffing, M.; et al. Third generation femtosecond technology. Optica 2014, 1, 45-63. [CrossRef]

20. Endo, A. Extendibility evaluation of industrial EUV source technologies for $\mathrm{kW}$ average power and 6.x $\mathrm{nm}$ wavelength operation. J. Mod. Phys. 2014, 5, 285-295. [CrossRef]

21. Pagania, C.; Saldin, E.L.; Schneidmiller, E.A.; Yurkov, M.V. Design considerations of 10 kW-scale, extreme ultraviolet SASE FEL for lithography. Nucl. Instrum. Methods Phys. Res. A 2001, 463, 9-25. [CrossRef]

22. Endo, A. High-brightness solid-state lasers for compact short-wavelength sources. In High Energy and Short Pulse Lasers; Viskup, R., Ed.; InTech: Rijeka, Croatia, 2016; pp. 101-128. Available online: https: / www.intechopen.com/books/high-energy-and-short-pulse-lasers/high-brightness-solidstate-lasers-for-compact-short-wavelength-sources (accessed on 7 September 2016). [CrossRef]

23. Graves, W.S.; Bessuille, J.; Brown, P.; Carbajo, S.; Dolgashev, V.; Hong, K.H.; Ihloff, E.; Khaykovich, B.; Lin, H.; Murari, K.; et al. Compact X-ray source based on burst-mode inverse Compton scattering at $100 \mathrm{kHz}$. Phys. Rev. Accel. Beams 2014, 17, 120701. [CrossRef] 
24. Chyla, M.; Miura, T.; Smrz, M.; Jelinkova, H.; Endo, A.; Mocek, T. Optimization of beam quality and optical-to-optical efficiency of Yb:YAG thin-disk regenerative amplifier by pulsed pumping. Opt. Lett. 2014, 39, 1141-1144. [CrossRef] [PubMed]

25. Smrž, M.; Miura, T.; Chyla, M.; Nagisetty, S.S.; Novák, O.; Endo, A.; Mocek, T. Supression of nonlinear phonon relaxation in Yb:YAG thin disk via zero phonon line pumping. Opt. Lett. 2014, 39, 4919-4922. [CrossRef] [PubMed]

26. Stenersen, K.; Wang, G. New direct optical pump schemes for multiatmosphere $\mathrm{CO}_{2}$ and $\mathrm{N}_{2} \mathrm{O}$ lasers. IEEE J. Quantum Electron. 1989, 25, 147-153. [CrossRef]

27. Novák, O.; Miura, T.; Smrž, M.; Chyla, M.; Nagisetty, S.S.; Mužík, J.; Linnemann, J.; Turčičová, H.; Jambunathan, V.; Slezák, O.; et al. Status of the high average power diode-pumped solid state laser development at HiLASE. Appl. Sci. 2015, 5, 637-665. [CrossRef]

28. Smrž, M.; Mužík, J.; Novák, O.; Chyla, M.; Turčičová, H.; Nagisetty, S.S.; Huynh, J.; Miura, T.; Linnemann, J.; Severová, P.; et al. Progress in kW-class picosecond thin-disk laser development at the HiLASE. In Proceedings of the SPIE Photonics West, Solid State Lasers XXV: Technology and Devices, San Francisco, CA, USA, 13-18 February 2016; Volume 9726, p. 972617.

29. Mužík, J.; Smrž, M.; Chyla, M.; Kubeček, V.; Endo, A.; Mocek, T. Development of a variable repetition rate, $\mathrm{kW}$-level, picosecond ring regenerative amplifier. In Proceedings of the CLEO/Europe EQEC Proceedings, Munich, Germany, 25-29 June 2017.

30. Mužík, J.; Smrž, M.; Chyla, M.; Novak, O.; Kubeček, V.; Endo, A.; Mocek, T. 4-mJ, 50-kHz picosecond pulses from PERLA C thin-disk laser platform. In Proceedings of the SPIE Photonics Optics + Optoelectronics, Prague, Czech Republic, 24-27 April 2017.

31. Smrž, M.; Chyla, M.; Novák, O.; Miura, T.; Endo, A.; Mocek, T. Amplification of picosecond pulses to $100 \mathrm{~W}$ by an Yb:YAG thin-disk with CVBG compressor. In Proceedings of the SPIE, Prague, Czech Republic, 14-15 April 2015; Volume 9513, pp. 951304-1-951304-7.

32. Chyla, M.; Nagisetty, S.S.; Zhou, H.; Smrž, M.; Endo, A.; Mocek, T. High-energy burst pulse amplification in PERLA B Thin-Disk Laser Platform. In Proceedings of the SPIE Photonics Optics + Optoelectronics, Prague, Czech Republic, 24-27 April 2017.

33. Fan, T.Y.; Ripin, D.J.; Aggarwal, R.L.; Ochoa, J.R.; Chann, B.; Tilleman, M.; Spitzberg, J. Cryogenic Yb ${ }^{3+}$-doped solid-state lasers. IEEE J. Sel. Top. Quantum Electron. 2007, 13, 448-459. [CrossRef]

34. Körner, J.; Jambunathan, V.; Hein, J.; Seifert, R.; Loeser, M.; Siebold, M.; Schramm, U.; Sikocinski, P.; Lucianetti, A.; Mocek, T.; et al. Spectroscopic characterization of $\mathrm{Yb}^{3+}$-doped laser materials at cryogenic temperatures. Appl. Phys. B 2014, 116, 75-81. [CrossRef]

35. Sikocinski, P.; Novak, O.; Smrz, M.; Pilar, J.; Jambunathan, V.; Jelinkova, H.; Endo, A.; Lucianetti, A.; Mocek, T. Time-resolved measurement of thermally induced aberrations in a cryogenically cooled Yb:YAG slab with a wavefront sensor. Appl. Phys. B 2016, 122, 73. [CrossRef]

36. Nagisetty, S.S.; Severova, P.; Miura, T.; Smrž, M.; Kon, H.; Uomoto, M.; Shimatsu, T.; Kawasaki, M.; Higashiguchi, T.; Endo, A.; et al. Lasing and thermal characteristics of Yb:YAG/YAG composite with atomic diffusion bonding. Laser Phys. Lett. 2017, 14, 015001. [CrossRef]

37. Shimatsu, T.; Uomoto, M. Atomic diffusion bonding of wafers with thin nanocrystalline metal films. J. Vac. Sci. Technol. B 2010, 28, 706-714. [CrossRef]

38. Chyla, M.; Nagisetty, S.S.; Severova, P.; Miura, T.; Mann, K.; Endo, A.; Mocek, T. Time-resolved deformation measurement of Yb:YAG thin disk using wavefront sensor. In Proceedings of the SPIE Photonics West, Laser Resonators, Microresonators, and Beam Control XVII, San Francisco, CA, USA, 3 March 2015; Volume 9343, p. $93431 \mathrm{E}$.

39. Tittel, F.; Richter, D.; Fried, A. Mid-infrared laser applications in spectroscopy. In Solid-State Mid-Infrared Laser Sources; Springer: Berlin/Heidelberg, Germany, 2003; Volume 89, pp. 445-510.

40. Popmintchev, T.; Chen, M.; Popmintchev, D.; Arpin, P.; Brown, S.; Alisauskas, S.; Andriukaitis, G.; Baliunas, T.; Mück, O.D.; Pugzlys, A.; et al. Bright coherent ultrahigh harmonics in the keV X-ray regime from mid-infrared femtosecond lasers. Science 2012, 336, 1287-1291. [CrossRef] [PubMed]

41. Xu, G.; Jovanovic, I.; Arab, E.; Hoang, P.; Musumeci, P.; O’Shea, B.; Rosenzweig, J.; Murokh, A.; Ovedenko, A.; Tikhoplav, R.; et al. A $5 \mu \mathrm{m}$ wavelength laser for dielectric laser acceleration. Adv. Accel. Concepts 2012, 1507, 893-898. [CrossRef] 
42. Schliesser, A.; Picqué, N.; Haensch, T.W. Mid-infrared frequency combs. Nat. Photonics 2012, 6, 440-449. [CrossRef]

43. Stubenvoll, M.; Schäfer, B.; Mann, K.; Novak, O. Photothermal method for absorption measurements in anisotropic crystals. Rev. Sci. Instrum. 2016, 87, 023904. [CrossRef] [PubMed]

44. Mori, Y.; Sasaki, T. Development of new NLO borate crystals. Bull. Mater. Sci. 1999, 22, 399-403. [CrossRef]

45. Turcicova, H.; Novak, O.; Smrz, M.; Miura, T.; Endo, A.; Mocek, T. Picosecond pulses in deep ultraviolet $(257.5 \mathrm{~nm}$ and $206 \mathrm{~nm}$ ) and mid-IR produced by a high-power $100 \mathrm{kHz}$ solid-state thin-disk laser. In Proceedings of the SPIE Photonics Europe, Laser Sources and Applications III, Brussels, Belgium, 3-7 April 2016; Volume 9893, p. 989302.

46. Yap, Y.K.; Inoue, T.; Sakai, H.; Kagebayashi, Y.; Mori, Y.; Sasaki, T.; Deki, K.; Horiguchi, M. Long-term operation of CsLiB6O10 at elevated crystal temperature. Opt. Lett. 1998, 23, 34-36. [CrossRef] [PubMed]

(c) 2017 by the authors. Licensee MDPI, Basel, Switzerland. This article is an open access article distributed under the terms and conditions of the Creative Commons Attribution (CC BY) license (http://creativecommons.org/licenses/by/4.0/). 